\title{
Algumas experiências profissionais acerca da construção do diagnóstico do TDAH
}

\author{
Rosana Vera de Oliveira Schicotti, ${ }^{I} \star$ Jorge Luis Ferreira Abrão, II Sérgio Augusto Gouveia JúniorIII \\ ${ }^{I}$ Universidade do Oeste Paulista, Presidente Prudente, SP, Brasil \\ "I Universidade Estadual Paulista, Assis, SP, Brasil \\ III Universidade Estadual Paulista, Presidente Prudente, SP, Brasil
}

\begin{abstract}
Resumo
Este artigo versa sobre experiências profissionais ocorridas entre 2005 e 2009 e tem como tema a construção do diagnóstico do Transtorno do Déficit de Atenção/Hiperatividade (TDAH). As práticas exercidas por uma orientadora educacional e psicóloga e por um professor produziram questionamentos derivados de referenciais histórico-críticos os quais constataram que o diagnóstico do TDAH pode estar ocupando o lugar de diversas ausências e conflitos na contemporaneidade, tais como a dificuldade de lidar com a diversidade dos diferentes modos de existência e a de estabelecer interditos e valores morais para nortear a convivência com toda a multiplicidade humana.
\end{abstract}

Palavras-chaves: TDAH; disciplinamento; infância; juventude; pós-modernidade.

\section{Some professional experiences about the construction of diagnosis of ADHD}

\begin{abstract}
This article delves into the professional experiences occurred during the period from 2005 to 2009; its main subject deals with the construction of diagnosis of Attention Deficit Disorder / Hyperactivity Disorder (ADHD). The practices exercised by a guidance counselor and psychologist, along with a Professor, produced many problematizations. These experiences were all derived from critical historical references which found that the diagnosis of ADHD may be taking the place of several absences and conflicts in contemporary times, such as the difficulty of dealing with the diversity of the different modes of existence, as well as with establishing prohibitions and moral values in order to guide the interaction with all human multiplicity.
\end{abstract}

Keywords: ADHD; discipline; childhood; youth; postmodernity.

\section{Introdução}

Há cerca de treze anos temos trabalhado com os temas da infância e da juventude; ao longo desse tempo todo, aconteceram diversas práticas profissionais, acadêmicas e pessoais instigantes - principalmente no que tange à disciplina escolar, ao estabelecimento de limites $\mathrm{e}$ aos diagnósticos de Transtorno do Déficit de Atenção/Hiperatividade, doravante TDAH. Sempre vimos os professores muito preocupados em solucionar as ocorrências de indisciplina em suas salas de aula, ou em lidar com a "falta de limites das crianças", como eles mesmos diziam. Existia presente - além da preocupação com a disciplina escolar - o esforço e o interesse por parte dos educadores para compreender os diagnósticos que surgiam em seu cotidiano. Eles queriam entender o que eram os denominados distúrbios de aprendizagem, dislexia, discalculia e outros supostos transtornos específicos da infância e do processo de escolarização.

O tema do disciplinamento da infância e da juventude ocupou-nos durante algum tempo, convidou-nos a estudá-lo mais atentamente, instigou-nos a construir alguns trabalhos teóricos (SCHICOTTI, 2005; SCHICOTTI; YAZLLE, 2011; SCHICOTTI, 2013) e incentiva-nos a escrever esse texto.

\footnotetext{
^Endereço para correspondência: Universidade do Oeste Paulista - UNOESTE. Rua José Bongiovani, 700 - Jardim Bongiovani. CEP: 19050920 - Presidente Prudente, SP - Brasil.E-mail: rvera oliveira@uol.com.br, abrão@assis.unesp. br, sagouveiajr@gmail.com
}

Dentro deste tema tão amplamente discutido na atualidade, pretendemos realizar - inspirados nas palavras de Figueiredo (2010, p. 146), segundo o qual a "[...] questão que se coloca é a de como fazer da experiência uma boa base para a produção de conhecimentos"- um breve histórico da construção do diagnóstico do Transtorno do Déficit de Atenção e Hiperatividade. Também buscaremos, a partir de algumas reflexões partindo de nossas leituras e vivências, analisar como este diagnóstico ocupa atualmente o lugar da moral e da disciplina na educação das crianças, bem como demonstrar as fragilidades e controvérsias dessa patologia - que já adquiriu diversas nomenclaturas ao longo de seus cem anos de existência.

O presente artigo basear-se-á nas vivências profissionais exercidas por duas pessoas: uma orientadora educacional de uma escola particular e psicóloga de uma ONG e um professor de língua portuguesa nos anos finais do Ensino Fundamental e do último ano do Ensino Médio. Ambos exerceram suas funções e coletaram dados em uma cidade do interior paulista durante o período de 2005 a 2009. Assim, para a descrição desses trabalhos, serão relatados acontecimentos vivenciados na escola em que se desenvolveu a experiência profissional e o caso de um menino atendido em psicoterapia na ONG. Em relação ao caso, optou-se por apresentar alguns dados colhidos durante as entrevistas iniciais com a família e uma síntese do trabalho realizado. Isto é, não serão descritos relatos de sessões do atendimento psicoterápico realizado. É imprescindível assinalar que compartilhamos da 
ideia de que os saberes psicológicos e/ou científicos somente podem ser produzidos em determinados contextos socioculturais específicos, e que um dos maiores desafios para o psicólogo, conforme Figueiredo (2009, p. 126) é conseguir manter um nível ótimo de tensão entre as experiências e os discursos representacionais:

não se trata de pensar apenas a proximidade e complementaridade entre teorias e práticas, mas de pensar suas distâncias e diferenças: manter a tensão é deixar que a prática seja um desafio à teoria e que a teoria deixe que irrompam problemas para a prática.

Com efeito, é esse nível ótimo de tensão que pretendemos manter nesse trabalho, dando assim significado às experienciais pessoais vivenciadas, bem como à história da construção do diagnóstico do TDAH. Dessa maneira, a partir do relato das vivências do grupo, serão expostos o percurso histórico, o processo de disciplinamento da infância e finalmente as conclusões que foram apreendidas de todo o trabalho de articulação entre as experiências e os conhecimentos teóricos apropriados.

\section{As vivências da psicóloga e orientadora educacional e do professor}

\section{Da psicóloga e orientadora educacional: ${ }^{1}$}

Quando fui trabalhar em uma escola particular como orientadora educacional ${ }^{2}$ durante o periodo de 2005 até 2007, a problemática do diagnóstico do TDAH aparecia constantemente em meu dia-a-dia: diagnósticos e pareceres me chegavam às mãos com frequência, queixas e dúvidas dos professores e pais eram rotina e crianças medicadas com Ritalina ${ }^{3}$ ou Concerta eram grande fonte de preocupação. Durante o periodo de graduação, pouco ou quase nada eu havia escutado sobre esse assunto e, então, trabalhando como psicóloga, entender o que significava esse transtorno tornou-se uma necessidade. Quando comecei a atuar como psicóloga clínica em uma ONG durante os anos de 2008 e 2009, os mesmos questionamentos apareciam.

\section{Do professor:}

Em minha atuação nas escolas em que trabalho, foi frequente o incômodo de ter de lidar com supostos casos de TDAH sem me sentir devidamente preparado para eles, sem ver pais dos alunos diagnosticados se esforçando para que seus filhos - embora diagnosticados com um "problema psicológico" - dominassem minimamente os conceitos oferecidos pelo "saber historicamente construido" (SAVIANI, 2002) e, sobretudo, sem confiar plenamente nos diagnósticos que chegavam aparentemente sem critério cientifico.

\section{Impressões dos dois:}

O que mais nos chamou a atenção, durante esse período, foi o fato de que alguns alunos que atendíamos, nos quais não se percebia nenhum sintoma que pudesse ser associado ao diagnóstico de TDAH, foram encami-

\footnotetext{
Os relatos que estão diferenciados em itálico, bem como na primeira pessoa do singular, visam registrar o depoimento pessoal dos autores.

${ }^{2}$ Como na escola não havia o cargo de psicóloga escolar, a profissional referenciada foi registrada como orientadora educacional. Porém, devido à sua formação e ao próprio trabalho realizado, a função exercida encaixava-se mais adequadamente à prática da psicologia escolar.

${ }^{3}$ Nome comercial do metilfenidato, psicoestimulante do sistema nervoso central.
}

nhados, por intermédio da escola, para psicólogos que os avaliaram como portadoras desse distúrbio. Começamos então a pensar que talvez o TDAH tivesse se tornando uma panacéia que poderia explicar muitos dos problemas que as escolas e os pais estão tendo com as crianças, dentre eles a dificuldade para estabelecer um referencial ético-moral sólido e coerente para ser transmitido às novas gerações. $\mathrm{O}$ trabalho ético-político-subjetivo parecia ter sido substituído por soluções mais práticas e imediatistas. Os valores se nos mostravam, como afirma Bauman (2000), demasiado inconsistentes; e parecíamos ver pais e psicopedagogos de plantão aplaudindo o que La Taille (2009) aponta como um distanciamento dos compromissos éticos e morais apresentados e impostos como desafios do contemporâneo. Ficava-nos evidente, como profissionais e pesquisadores, a necessidade de pesquisar mais essas questões.

Encontramos mais sustentação para nossos questionamentos em alguns autores que analisaram essa temática: Aquino (2003), Moysés e Collares (2011) e Legnani et al. (2004). Para eles, está acontecendo, em uma escala acelerada, um processo de patologização da clientela escolar. Aquino (2003, p. 36) conclui:

É certo, portanto, que um inadiável trabalho ético-político se impõe aos educadores atuais: problematizar a demanda psicologizante que parece reinar entre uma parcela crescente dos profissionais da educação, demanda essa que tem como resposta a questionável oferta de uma vasta gama de serviços parapedagógicos.

Legnani (LEGNANI et al., 2004) também levantou a questão de como são feitos os diagnósticos de TDAH. Parafraseando a autora, podemos dizer que o processo de patologização focaliza apenas a criança e sua "doença orgânica", pois os vários profissionais que diagnosticam o aluno se esquecem de fazer um questionamento crítico acerca das condições que foram geradoras da queixa escolar. Ela afirma que muitas vezes não se analisam - no processo psicodiagnóstico - aspectos importantes como a qualidade das relações que circundam o sujeito, bem como as condições de trabalho do professor e suas habilidades e suas competências.

Em nosso cotidiano escolar, o objetivo principal era propiciar a construção de uma educação humanizadora que possibilitasse o desenvolvimento integral do educando. Dentre as várias práticas que exercíamos na instituição, havia o projeto "Ensinar para a diversidade", cujo objetivo era auxiliar os alunos que apresentavam dificuldades de aprendizagem, inserindo-os no processo educacional. Era um trabalho que visava permitir que todos tivessem acesso ao conhecimento, superando dificuldades e desvelando talentos. Defendia-se que os alunos com dificuldades de aprendizagem não deveriam ser rotulados ou estigmatizados pela instituição; mas sim respeitados em suas singularidades.

No projeto "Ensinar para a diversidade", a escola solicitava que acompanhássemos os alunos com necessidades educativas especiais constatadas por meio de laudos técnicos de profissionais habilitados: médicos, psicólogos, 
psicopedagogos ou fonoaudiólogos. Desta forma, observamos vários pais cujos filhos apresentavam dificuldades de aprendizagem buscando auxílio nestes profissionais que atuavam em seus consultórios, externos à instituição escolar, para obter um parecer que comprovasse algum diagnóstico. No caso do diagnóstico do TDAH, o processo geralmente começava com a iniciativa de alguns pais de alunos com suspeita deste transtorno, os quais traziam questionários para os professores responderem. As questões abrangiam temas que principalmente indagavam o comportamento do aluno na sala de aula e eram baseadas nos critérios estabelecidos pelo Manual Diagnóstico e Estatístico de Transtornos Mentais - DSM-4 (ASSOCIAÇÃO PSIQUIÁTRICA AMERICANA [APA], 2000). ${ }^{4}$

Notávamos que esses questionários tornavam-se uma constante no cotidiano do professor e que, muitas vezes, os docentes mostravam-se bastante desmotivados para respondê-los, pois eles se misturavam aos outros documentos da burocracia institucional. Alguns chegavam a afirmar ironicamente que deveriam receber mais para responder àquelas perguntas que eram solicitadas pelos pais ou pelo psicólogo da criança. Em nenhum momento recebemos do profissional responsável pelos diagnósticos de TDAH uma visita à escola para conhecer os professores ou mesmo para esclarecê-los da importância daqueles questionários. Recebemos, entretanto, algumas fichas sem nem mesmo o preenchimento com o nome do aluno que se buscava diagnosticar como portador de TDAH.

Diante desse quadro repleto de contradições e questionamentos, enveredamo-nos por uma perspectiva que não focalizasse apenas a patologia em si, mas que se ampliasse para os fatos sociais constitutivos dessa realidade, caminho que já foi trilhado por muitos autores que trabalharam com essa problemática (MOYSÉS; COLLARES, 1992; LEGNANI; ALMEIDA, 2008, CALIMAN, 2010), os quais ofereceram subsídios para que pudéssemos traçar nosso próprio percurso.

\section{O percurso histórico}

Caliman (2010) oferece-nos uma valiosa contribuição para a história do diagnóstico do TDAH. A autora fez uma cartografia dos discursos históricos sobre essa temática, dentre os aspectos levantados por ela destacamos a ideia de que a história do TDAH guarda-chuva é constituída por outros diagnósticos guarda-chuvas. Citando Rafalovich (2002 apud CALIMAN, 2010) a autora demonstra que esse transtorno é uma pletora de sintomas diferenciados, que possui em sua biografia a presença de outros diagnósticos também imprecisos e abrangentes, como a síndrome da encefalite letárgica e a lesão cerebral mínima, patologias comumente associadas à história do TDAH (MOYSÉS; COLLARES, 1992; LEGNANI; ALMEIDA, 2008). Pois bem, na sintomatologia apresentada pelos manuais diagnósticos da psiquiatria, pode caber quase tudo: defeito no controle moral, transtorno de comportamento e de aprendizado... Há um excesso de sintomas diferenciados e abrangentes na descrição patológica, de modo que é muito comum confundir TDAH com outros transtornos

${ }^{4}$ É importante esclarecer que, durante o período da experiência profissional relatada, era o DSM-4 que orientava o diagnóstico de transtornos mentais.

Fractal, Rev. Psicol., v. 28 - n. 1, p. 55-62, 2016 psiquiátricos que possuem um quadro patológico semelhante. Também é interessante apontar que a história dos distúrbios de aprendizagem contada por Moysés e Collares (1992) encontra-se com a história do TDAH. Há vários pontos em comum entre ambos os percursos históricos desses "distúrbios" tão presentes na vida escolar; nessa mesma obra, coloca-se, por exemplo, como ponto de convergências entre ambas as histórias, a nomeação da Desordem do Déficit de Atenção (DDA) em 1980 pela Academia Americana de Psiquiatria, visto que dentre as características essenciais deste transtorno estaria frequente a presença dos distúrbios de aprendizagem.

Atualmente o DSM-5 (APA, 2014), a quinta edição do Manual Diagnóstico e Estatístico de Transtornos Mentais, reconhece os Transtornos Específicos da Aprendizagem e o TDAH como duas patologias distintas que possuem características próprias. Entretanto, ambos os transtornos podem estar correlacionados, formandos as chamadas comorbidades. Rohde et al. (2000), por exemplo, afirmam haver alta taxa de comorbidade entre o TDAH e outras doenças, entre elas: a depressão $(15 \%$ a $20 \%)$, transtorno de ansiedade $(25 \%)$ e transtornos da aprendizagem (10\% a 25\%). O DSM-5, por sua vez, aponta que o transtorno de oposição desafiante, o transtorno da personalidade antissocial, o transtorno da conduta, entre outros, são comórbidos com o TDAH. Também o DSM-5 subdivide o TDAH em três subtipos, cuja sintomatologia será resumida abaixo:

- Apresentação predominantemente desatenta, tais como: não presta atenção em detalhes ou comete erros por descuido em tarefas escolares e de trabalho; dificuldade de manter a atenção em tarefas ou atividades lúdicas; perder coisas necessárias para tarefas ou atividades, etc.

- Apresentação predominantemente hiperativa/impulsiva: remexer ou batucar as mãos ou os pés ou se contorce na cadeira; correr ou subir nas coisas em situações em que isto é inapropriado, deixar escapar uma resposta antes que a pergunta tenha sido concluída; interromper ou se intrometer nas conversas, etc.

- Apresentação combinada: caracteriza-se pela combinação dos dois subtipos anteriores.

Como já foi colocado, oferecemos apenas alguns exemplos dos sintomas característicos do TDAH apresentados pelo Manual Diagnóstico e Estatístico de Transtornos Mentais (DSM-5). Ao todo são 18 características, as nove primeiras se referem à desatenção e as seguintes a hiperatividade e impulsividade. Temos a impressão - ao analisarmos mais detidamente essa sintomatologia - de que ela está mais relacionada com um juízo de valor ou moral do que com uma postura científica imparcial. Como afirmam Moysés e Collares (2011) e Aquino (2003) - é muito difícil alguma criança e até um adulto não se sentir incluído nos critérios diagnósticos estabelecidos.

Ao entrarmos em contato com termos tão carregados de terminologia médica, torna-se imprescindível discutir o processo de medicalização da educação. Moysés 
e Collares (1992) questionam como poderíamos discutir seriamente uma doença que se caracteriza pelos sintomas estabelecidos pelo DSM-5, dentre eles: "Com frequência é incapaz de brincar ou se envolver em atividades de lazer calmamente", "mete-se nas conversas", "aguardar em uma fila", etc:

A ironia talvez seja a única forma possível de reação, além do susto. Como discutir seriamente uma "doença que se caracteriza por esses 'sintomas"'? Como lidar com tal intensidade de biologização da sociedade? Sociedade que aceita e anseia por esse processo! (MOYSÉS; COLLARES, 1992, p. 45).

São questões que tem sido problematizadas em diversos contextos sociais, por meio de congressos, debates e movimentos que propõem outras alternativas (diferentes da medicalização) que possam contribuir com o desenvolvimento e a potencialização das capacidades infantis. Diagnosticar como doença a presença de comportamentos que - embora tipicamente humanos - são incômodos para uma normalidade construída e naturalizada não pode deixar de nos evocar reflexões que Santos e Sampaio (2012) - utilizando-se de Nietzsche, Foucault e Freud - fazem sobre o que se elege como comportamento adequado e o que se faz para evitar os desvios que indivíduos supostamente cometam.

\section{O TDAH e o processo de disciplinamento da infância}

Adentrando mais detidamente na história da infância, verificamos que o processo de disciplinamento de crianças não se inicia agora com o surgimento do TDAH, para Caliman (2010, p. 55): “A preocupação com a vida moral e educacional da criança é um assunto médico desde a primeira metade do século XIX”. Discutimos essa temática em um trabalho anterior (SCHICOTTI; YAZLLE, 2011) ao refletir como o processo de higienização ocorrido durante as quatro primeiras décadas do século XX no Brasil representou o lugar da disciplina, da eficiência, da moldagem e da adaptação.

Gondra (2000) relata-nos que a Higiene foi um ramo da medicina que se deteve nos objetos sociais, isto é, a partir do final do século XIX, a vida social e a educação escolar transformaram-se em objetos da medicina, expandindo, assim, o saber médico. Nesse período da história brasileira, o grande desafio era organizar um Estado Nacional. Sendo assim, as propostas ditas científicas, entre as quais estavam as propostas ligadas à medicina, tiveram um papel preponderante na formulação de políticas públicas voltadas para a saúde, educação, infra-estrutura, assistência social, entre outras.

Abrão (2001) também aponta a grande influência que a psiquiatria brasileira da década de 1920, fundada em um ideal eugênico, exerceu sobre a criação das clínicas de orientação infantil. Estas tinham como proposta de atendimento uma intervenção no âmbito familiar e escolar, atuando principalmente na prevenção da doença mental, estendendo desta maneira o saber da medicina orgânica para a psiquiatria.

Vale ressaltar que, segundo Kuhlmann Júnior (2001), as descobertas de Pasteur, como as relações entre microorganismos e doenças e a pasteurização do leite de vaca, foram importantes para que os médicos tivessem uma grande influência nas discussões sobre a criança, já que essas descobertas científicas entraram em consonância com os ideais da época, aliando-se aos objetivos de modernidade e civilidade.

O mesmo raciocínio empregado nas descobertas de Pasteur e na compreensão da encefalite letárgica, patologia mental apontada como precursora do TDAH, que reunia sintomas diversos, característicos das patologias orgânicas e das psicogênicas (CALIMAN, 2010) surgida no início do século XX, compõem o quadro científico hegemônico da nossa época. Como apontam Moysés e Collares (1992), a epidemia infecciosa de encefalite letárgica nos Estados Unidos produziu altas taxas de morbidade e mortalidade, as pessoas que sobreviveram a ela apresentaram sequelas neurológicas, com mudanças de comportamento e/ou de funções intelectuais. Este fato possibilitou que se pudesse, cada vez mais, vincular as descobertas da neurologia com a pesquisa laboratorial e, principalmente, inferir que as funções intelectuais estão intimamente ligadas aos substratos cerebrais/orgânicos.

Sabemos o quanto é importante para medicina organicista visualizar a(s) causa(s) da patologia invisível. É em virtude disso, que se procura insistentemente uma motivação cerebral e neurológica para a patologia do TDAH por meio das tecnologias de imagem cerebral. Ao mesmo tempo em que se procura legitimar esse transtorno por meio dessas tecnologias, abordando a existência de circuitos neuronais responsáveis pela sintomatologia do TDAH, não se percebe a sua utilização efetiva no cotidiano das pessoas que são diagnosticadas. Em nossa experiência profissional, não observamos nenhuma criança, nem mesmo aquelas provenientes de classes sociais mais abastadas, realizar exames de neuroimagem (NI) para detectar o substrato neuroquímico do transtorno.

Em uma entrevista com o neurobiólogo Eric Kandel, realizada pela Folha de São Paulo no dia 02 de novembro de 2011, pôde-se ler a seguinte afirmação em relação ao uso do DSM-4:

A preocupação com a objetividade foi introduzida há uns

20 anos quando houve uma tentativa de validar os critérios do manual para descrever transtornos. Isso foi extremamente importante para que diferentes psiquiatras pudessem dar o mesmo diagnóstico a um mesmo paciente. [...] Nós, psiquiatras, ainda temos que recorrer à história do paciente. Precisamos desesperadamente de bons marcadores biológicos. Sem isso, podemos publicar quantas edições quisermos do manual, que não chegaremos a lugar nenhum (KANDEL, 2011, online).

O posicionamento de Kandel demonstra certa decepção ou desalento com o fato de a psiquiatria ainda ter que recorrer à narrativa do sujeito para realizar seus diagnósticos. Sabemos que o grande anseio pela objetividade e pela neutralidade científica nasce com o advento da ciência moderna, e parece-nos que é ainda o modelo biológico que conseguiu corresponder a esses ideais. Vemos, na fala de Kandel e nos diagnósticos pré-maturos, o quanto as posturas contemporâneas de patologização e medicaliza- 
ção estão distantes de abarcar a complexidade da existência humana. Green (2008) cita a ideia de pensamento hipercomplexo de Morin, mostrando o quanto ela se aproxima da psicanálise, pois é um tipo de pensamento que aceita as incertezas, as liberdades, e as desordens. Para Morin (apud GREEN, 2008, p. 344): “O espírito-cérebro individual é mais complexo que a sociedade, mais complexo que a Terra, mais complexo que a galáxia".

Quando realizamos uma crítica ao processo de medicalização da vida - não estamos desconsiderando a existência de doenças reais ou ignorando os avanços da pesquisa biológica; estamos apenas assinalando as graves consequências que a biologização do humano acarreta para a exclusão do sujeito, tornando-o impotente para criar recursos próprios de enfrentamento de sua condição humana (GUARIDO, 2011; MOYSÉS; COLLARES, 2011). Diversos autores como Foucault (1987), Cambi (1999) e Guirado (1996) apontaram o caráter imanentemente disciplinar da Modernidade. Foucault (1987) estuda a metamorfose dos métodos punitivos em sua obra Vigiar e Punir: já nas primeiras páginas ele problematiza como o suplício ou o sofrimento físico aplicado ao criminoso foi substituído pela privação da liberdade, ocorrendo o que ele denomina de "suavidade penal como técnica de poder" (FOUCAULT, 1987, p. 26-27); ao analisar o sistema penal, oferece-nos uma nova forma de compreender o poder evidenciando-nos que, antes de a burguesia se tornar a classe politicamente dominante, o poder estava concentrado na figura do soberano, os criminosos não participavam do julgamento e toda a investigação a respeito do crime era realizada em segredo, pois o direito de punir estava nas mãos do soberano. Segundo ele, é somente a partir do século XVIII que a punição passa a ser uma defesa da sociedade, que cria instituições disciplinadoras como a escola, o quartel e o hospital, com cujas semelhanças devemos nos indignar: "devemos ainda nos admirar que a prisão se pareça com as fábricas, com as escolas, com os quartéis, com os hospitais, e todos se pareçam com as prisões?" (FOUCAULT, 1987, p. 199). Guirado (1996), também orientada em Foucault, afirma que em cada época vai existir uma determinada estratégia de poder. $\mathrm{Na}$ Modernidade, a estratégia predominante é o poder disciplinar, pois o poder deixa de concentrar-se em lugares específicos e torna-se disperso, difuso, microfísico.

Neste sentido, levando em conta os ideais iluministas, podemos dizer que, ao valer-se de um quadro jurídico igualitário e defendendo um regime de tipo parlamentar e representativo, as "Luzes" libertaram, mas fabricaram também os dispositivos disciplinares. Estes têm a função de ordenar as multiplicidades humanas, objetivando obediência, utilidade e adestramento dos corpos, a fim de permitir a ampliação dos aparelhos de produção. As disciplinas, dessa forma, podem ser tomadas como técnicas de um poder que irá possibilitar a produção de saber e de aptidões nas instituições (escolas, hospitais, prisões).

Caliman (2006), em sua tese de doutorado, analisou a constituição do diagnóstico do TDAH no interior do processo histórico de biologização moral da atenção. Os estudos dessa autora nos fazem refletir o quanto a constituição do indivíduo atento e desatento faz parte de um processo histórico de controle moral. Nesta perspectiva, o TDAH pode ser compreendido como mais uma técnica de disciplina e controle moral. Ela observou, por meio de sua pesquisa bibliográfica, que o TDAH retirou da família, do indivíduo diagnosticado, bem como dos professores, a responsabilidade por suas deficiências. Foram libertados do julgamento moral, mas atados às suas limitações corporais e físicas, devido a determinações naturais/genéticas/orgânicas. Também Kupfer (2007), em seu trabalho voltado para crianças autistas e psicóticas, afirma que uma biologização do autismo e das psicoses “desculpabilizou” as mães ao buscar explicações somente em falhas dos neurotransmissores, retirando da família a parte que lhe cabe na criação de seus filhos.

Heller (1999) complementa a nossas reflexões. Ao discutir as peculiaridades do mundo moderno, a autora coloca que há uma diferença fundamental entre as civilizações pré-modernas e modernas. De acordo com ela, as primeiras têm um tipo de estratificação hierárquica bem-determinada e praticamente sem mobilidade na origem; já as últimas oferecem ao indivíduo possibilidades ilimitadas, pois não impõem valores nem delimitações. Para a autora, o mundo inteiro já se tornou moderno, o que nos leva a vivenciar tanto a possibilidade da liberdade pessoal e política, quanto a perda das tradições e da segurança, mas viver na incerteza de significados e de valores pode ser extremamente traumático. Santos (1987), também salienta a falta de referências, mas acrescenta um limite: o dever de consumir que tem o indivíduo pós-moderno, tipicamente consumista, hedonista e narcisista. Vemos que é esse modus vivendi que leva - normalmente - ao mau rendimento escolar, e não algum problema biológico, cerebral.

Um caso atendido na ONG em que trabalhamos ilustra bem essas questões: a criança, que aqui será nomeada como João, tinha cerca de oito anos e recebeu o diagnóstico de TDAH. A queixa principal era escolar: João era muito distraído na sala de aula, tirava notas baixas e não fazia suas lições de casa. Sua família trouxe o relatório de uma psicóloga: constatação de TDAH com predomínio de Déficit de Atenção.

Assim, no período de maio de 2008, iniciaram-se os atendimentos com João, os quais se deram por meio de psicoterapia individual e orientações tanto à família quanto à escola. Nas primeiras sessões, João mostrou-se colaborativo e atento, demonstrando capacidade de aprendizagem e memorização, o que entrava em contradição com suas experiências escolares e com o diagnóstico de desatenção. Todavia, assim como uma paixão fugaz, aquilo que inicialmente prenunciava um vínculo forte e duradouro foi se transformando e esvanecendo, e a relação não foi a termo. Foram ocorrendo faltas consecutivas até que, em março de 2009, João foi desligado.

Pudemos absorver da história de João que, provavelmente, quem mais precisava de auxílio era a sua família. Infelizmente, na ONG não havia um trabalho sistemático de terapia familiar, visto que faltavam recursos humanos e materiais para tanto. No trabalho com a infância é de 
suma importância o acompanhamento de seus cuidadores, para que eles possam ter condições de acolhida e de responsabilidade com a criança. Tentou-se realizar isso por meio das orientações à família, entretanto não foi suficiente para produzir uma maior implicação desta no trabalho com o João.

Pudemos também perceber que João não vivenciava situações em sua família de modo que pudesse aprender a ser organizado e concentrado na escola. Sua vida, desde seu nascimento, teve como principal característica a instabilidade: sua mãe teve dois relacionamentos concomitantes e, quando engravidou, não sabia exatamente quem era o pai de seu filho; casou-se e - algum tempo depois - descobriu por meio de um exame de DNA que seu marido não era o pai biológico de João; separou-se e voltou a se casar, agora com outro homem; o menino, então, tinha três pais - o adotivo, o biológico e o atual marido da mãe.

Apesar de ter praticamente duas casas (os avós maternos auxiliavam na criação do menino e participaram das entrevistas iniciais) e possuir três figuras paternas, João muitas vezes parecia estar à deriva. $\mathrm{O}$ pai biológico era uma pessoa ausente na vida do filho, o adotivo envolveu-se com drogas e sempre tinha ligação com a polícia ou traficantes. $\mathrm{O}$ atual companheiro da mãe parecia cuidar do menino; entretanto, devido às constantes brigas com a esposa, havia sempre a ameaça de um novo divórcio. Na casa dos avós, João também vivenciava muitas brigas e discussões.

Durante o trabalho psicoterapêutico realizado com essa criança, percebemos que não havia adultos que a auxiliavam a mediar seus comportamentos impulsivos, bem como a lidar com seus desejos e a realidade da vida de um modo criativo e responsável. João não tinha estabilidade em sua vida familiar, não havia rotina em sua casa e seus próprios familiares desconfiavam do diagnóstico de TDAH, afirmando que o "problema" do menino era a falta de limites.

Verificamos que faltavam a João as relações de verticalidade social que Ramos e Nascimento (2008) indicam ser naturalizadas na família. Faltavam a João, ainda segundo os autores citados, a percepção e o reconhecimento de dois importantes fatores na constituição das instituições sociais e na interiorização das normas que elas estabelecem: a historicidade e a autoridade moral na família. Esta não apenas não se responsabilizou por trazer a criança nas sessões e concluir o trabalho psicoterapêutico, como também não se responsabilizava por acompanhar o menino nas lições de casa e levá-lo para as aulas de reforço. Em uma visita à escola, a professora cogitou: "Falta medicamento ou falta família".

As experiências vivenciadas por nós, assim como nossa pesquisa bibliográfica, têm resultados que ratificam outros autores (CALIMAN, 2006; GUARIDO, 2011) os quais verificaram na "epidemia" dos diagnósticos do TDAH a representação de um processo de biologização da vida, mais especificamente nas palavras de Caliman (2006) o transtorno referido faz parte de um processo de "biologização" e "cerebrização" da moral e da vontade. Verificamos, ainda, conforme evidenciam Santos e Sampaio (2012), o uso das ciências a serviço do ideal ascético, com a finalidade de disciplinar o indivíduo, compreendendo como patologias as condutas que fogem desse ideal.

$\mathrm{Na}$ contemporaneidade, tornou-se raro abster-se das tecnologias medicamentosas/biológicas para educar crianças e adolescentes. Nesse sentido, algumas pesquisas que utilizaram o método psicanalítico para compreender a questão do TDAH (LEGNANI, 2003; MANO, 2009) compreenderam que o aumento do diagnóstico deste transtorno está relacionado ao declínio da função paterna cuja significação na psicanálise pode ser sucintamente compreendida como a representação da Lei; outros estudiosos alertam para a diminuição de compromissos éticos do indivíduo contemporâneo (LA TAILLE, 2009) e para as rápidas mudanças da instituição família (RAMOS; NASCIMENTO, 2008). Dessa forma, perde representatividade a Lei - que pode ser compreendida como o representante ético-moral que regula as ações humanas, pois sem ela, sem uma ética, sem um norte, estamos sujeitos aos excessos, aos descontroles, à hybris.

\section{Considerações finais}

Nas experiências relatadas, entramos em contato com as inconsistências e contradições da construção do diagnóstico de TDAH e percebemos que tal constructo pode estar ocupando o lugar de diversas ausências e conflitos na contemporaneidade; um dos principais deles relaciona-se com a dificuldade de lidar com a diversidade dos diferentes modos de existência e de estabelecer interditos e valores morais para nortear a convivência com a multiplicidade humana.

Nosso trabalho como educadores e psicólogos, bem como a história de João, trouxe a reflexão de como a infância tem sido culpabilizada e violentada pela ineficácia da escola e dos adultos que são responsáveis por ela. $\mathrm{O}$ potencial de João era ofuscado e empobrecido pela falta de direcionamento, referência e cuidados básicos. Apesar do tempo reduzido de atendimento que tivemos com a criança (cerca de 10 meses), nesse período pudemos conhecer um pouco de seu funcionamento psíquico e histórico familiar, bem como a escola em que estudava, o que nos possibilitou fazer as reflexões sobre a construção do diagnóstico do TDAH. Todavia, devido à desistência da família, bem como às próprias deficiências e limitações de nossa atuação na $\mathrm{ONG}$, não pudemos finalizar o trabalho psicoterapêutico com a criança. Como dissemos, provavelmente faltou um trabalho mais sistematizado com o grupo familiar em nossa experiência.

Queremos ressaltar que nossa análise do caso estudado não pretendeu simplesmente culpabilizar a família, mas sim responsabilizá-la pela parte que lhe cabe na introdução da criança no mundo do humano e da linguagem (KUPFER, 2007). Concomitantemente a isto, queremos responsabilizar a escola por sua parte no processo de medicalização da infância, do ensino e da aprendizagem. Pudemos perceber, no contato com os professores e outros atores da instituição escolar, a carência de recursos 
criativos para desenvolver as potencialidades e superar as dificuldades de seus alunos. As alternativas pedagógicas têm se resumido à culpabilização da família e encaminhamentos aos serviços parapedagógicos.

Neste sentido, salientamos que este trabalho pretendeu principalmente demonstrar, por meio de nossas experiências profissionais, o quanto crianças saudáveis e inteligentes têm sido taxadas de portadoras de TDAH e medicadas desnecessariamente. Diagnósticos têm sido feitos às pressas, sem um conhecimento mais aprofundado sobre a história de vida do paciente e do contexto em que vive. E assim se fabricam indivíduos autômatos sem condições de crítica e de consciência sobre si e sobre o mundo em que habitam.

\section{Referências}

ABRÃO, J. L. F. A história da psicanálise de crianças no Brasil. São Paulo: Escuta, 2001.

AQUINO, J. G. Indisciplina: o contraponto das escolas democráticas. São Paulo: Moderna, 2003.

BAUMAN, Z. Modernidade líquida. São Paulo, J. Zahar, 2000.

CALIMAN, L. V. A Biologia Moral da Atenção: a constituição do sujeito (des) atento. 2006. Tese (Doutorado)-Universidade do Estado do Rio de Janeiro, Rio de Janeiro, 2006.

CALIMAN, L. V. Notas sobre a História Oficial do Transtorno do Déficit de Atenção/Hiperatividade TDAH. Psicologia Ciência e Profissão, Brasília, v. 30, n. 1, p. 45-61, mar. 2010.

CAMBI, F. História da pedagogia. São Paulo: Unesp, 1999.

ASSOCIAÇÃO PSIQUIÁTRICA AMERICANA. Manual Diagnóstico e Estatístico de Transtornos Mentais - DSM-4. 4. ed. Porto Alegre: Artes Médicas, 2000.

ASSOCIAÇÃO PSIQUIÁTRICA AMERICANA. Manual Diagnóstico e Estatístico de Transtornos Mentais - DSM-5. 5. ed. Porto Alegre: Artmed, 2014.

FIGUEIREDO, L. C. M. Revisitando as psicologias: da epistemologia à ética das práticas e discursos psicológicos. 5 . ed. Petrópolis, RJ: Vozes, 2009.

FIGUEIREDO, L. C. M. Epistemologia, História, e Além: reflexões sobre uma trajetória pessoal. Psicologia: Ciência e Profissão, Brasília, v. 30, n. esp., p. 140-147, 2010.

FOUCAULT, M. Vigiar e Punir: nascimento da prisão. Petrópolis, RJ: Vozes, 1987.

GONDRA, J. G. Medicina, higiene e educação escolar. In: LOPES, E. M. I.; FARIA FILHO, L. M.; VEIGA, C. G. (Org.). 500 anos de educação no Brasil. Belo Horizonte: Autêntica, 2000. p. 519-550.

GREEN, A. O saber científico. In: Orientações para uma psicanálise contemporânea. Rio de Janeiro: Imago, 2008, p. 317-349.

GUARIDO, R. A Biologização da vida e algumas implicações do discurso médico sobre a educação. In: CONSELHO REGIONAL DE PSICOLOGIA DE SÃO PAULO; GRUPO INTERINSTITUCIONAL QUEIXA ESCOLAR (Org.). Medicalização de crianças e adolescentes: conflitos silenciados pela redução de questões sociais a doenças de indivíduos. São Paulo: Casa do Psicólogo, 2011. p. 27-39.

GUIRADO, M. Poder indisciplina: os surpreendentes rumos da relação de poder. In: AQUINO, J. G. (Org.). Indisciplina na Escola: alternativas teóricas e práticas. 4. ed. São Paulo: Summus, 1996. p. 57-71.

HELLER, A. Uma crise global da civilização: os desafios futuros. In: HELLER, A. et al. A crise dos paradigmas em ciências sociais e os desafios para o século XXI. Rio de Janeiro: Contraponto, 1999. p. 13-32.

KANDEL, E. Entrevista Eric Kandel: Psiquiatria está em crise por falta de provas científicas. Folha de São Paulo, São Paulo, 2 nov. 2011. Disponível em: <http://www1.folha.uol.com.br/fsp/ saude/sd0211201101.htm>. Acesso em: 3 set. 2012.

KUHLMANN JÚNIOR, M. Infância e educação infantil: uma abordagem histórica. 2. ed. Porto Alegre: Mediação, 2001.

KUPFER, M. C. M. Educação para o futuro: psicanálise e educação. 3. ed. São Paulo: Escuta, 2007.

LA TAILLE, Y. Formação ética: do tédio ao respeito de si. Porto Alegre, RS: Artmed, 2009.

LEGNANI, V. N. Transtorno de Déficit de Atenção e Hiperatividade: um estudo psicanalítico. 2003. Tese (Doutorado)-Instituto de Psicologia, Universidade de Brasília, Brasília, 2003.

LEGNANI et al. Impasses na construção da noção de alteridade nos processos de subjetivação das crianças com o diagnóstico de transtorno de déficit de atenção e hiperatividade (TDA/H) Anais do 5 Col.S LEPSI IP/FE-USP Jun. 2004. Disponível em: <http://www.proceedings.scielo.br/scielo. php?pid=MSC0000000032004000100059\&script $=$ sci arttext>. Acesso em: 2 out. 2008.

LEGNANI, V. N.; ALMEIDA, S. F. C. A construção diagnóstica de Transtorno de Déficit de Atenção/Hiperatividade: uma discussão crítica. Arquivos Brasileiros de Psicologia, Rio de Janeiro, v. 60, n.1, p. 2-13, jan.-jun. 2008. Disponível em: $\quad<$ http://seer.psicologia.ufrj.br/index.php/abp/article/ view/174/159>. Acesso em: 3 set. 2012.

MANO, M. S. A criança hiperativa, a família, o discurso científico e a psicanálise. 2009. Dissertação (Mestrado)Universidade Estadual Paulista "Júlio de Mesquita Filho", Assis, 2009.

MOYSÉS, M. A. A; COLLARES, C. A. L. A história não contada dos distúrbios de aprendizagem. Cadernos CEDES, Campinas, n. 28, p. 31-48, 1992.

MOYSÉS, M. A. A; COLLARES, C. A. L. Dislexia e TDAH: Uma análise a partir da ciência médica. In: CONSELHO REGIONAL DE PSICOLOGIA DE SÃO PAULO; GRUPO INTERINSTITUCIONAL QUEIXA ESCOLAR (Org.). Medicalização de crianças e adolescentes: conflitos silenciados pela redução de questões sociais a doenças de indivíduos. São Paulo: Casa do Psicólogo, 2011. p. 71-110.

RAMOS, D.; NASCIMENTO, V. G. A família como instituição moderna. Fractal: Revista de Psicologia, Niterói, v. 20, n. 2, p. 461-472, jul./dez. 2008. Disponível em: <http://www.uff. br/periodicoshumanas/index.php/Fractal/article/view/97/158>. Acesso em: 3 set. 2012.

ROHDE, L. A. et al. Transtorno de déficit de atenção/ hiperatividade. Revista Brasileira de Psiquiatria, São Paulo, v. 22, s. 2, p. 7-11, dez. 2000.

SANTOS, J. F. O que é pós-moderno. São Paulo, Brasiliense, 1987. 
SANTOS, L. C.; SAMPAIO, W. M. Considerações sobre a civilização ocidental contemporânea em Nietzsche e Freud. Fractal: Revista de Psicologia, Niterói, v. 24, n. 1, p. 5980, jan./abr. 2012. Disponível em: <http://www.uff.br/ periodicoshumanas/index.php/Fractal/article/view/441/633>. Acesso em: 3 set. 2012.

SAVIANI, D. Pedagogia histórico-crítica: primeiras aproximações. Campinas, SP: Autores Associados, 2002.

SCHICOTTI, R. V. O. Concepções e práticas de educadores acerca de disciplina e limites na educação infantil: um estudo de caso. 2005. Dissertação (Mestrado)-Universidade Estadual Paulista, Assis, 2005.

SCHICOTTI, R. V. O.; YAZLLE, E. G. O disciplinamento da infância: algumas considerações históricas. Nucleus, v. 8, n. 1, p. 81-90, abr. 2011. Disponível em: <http://www.nucleus. feituverava.com.br/index.php/nucleus/article/view/543>. Acesso em: 7 dez. 2011.

SCHICOTTI, R. V. O. TDAH e infância contemporânea: um olhar a partir da psicanálise. 2013. Tese (Doutorado) Universidade Estadual Paulista, Assis, 2013.

Recebido em: 6 de outubro de 2012

Aceito em: 22 de outubro de 2015 